\title{
Immunoblot Analysis of Antibody Binding to Polypeptides of Borrelia burgdorferi in Children with Different Clinical Manifestations of Lyme Disease
}

\author{
D. NADAL, CH. TAVERNA, AND W. H. HITZIG \\ Division of Infectious Diseases and Immunology, Department of Pediatrics, University of Zurich, \\ Zurich, Switzerland
}

\begin{abstract}
We analyzed by means of immunoblot technique the patterns of antibodies binding to polypeptides of Borrelia burgdorferi $\mathrm{B31}$ in the sera of 21 children with different stages of Lyme disease. All sera but one recognized the flagellar protein $41 \mathrm{kD}$ and all but two the 83$\mathrm{kD}$ protein. The number of proteins recognized rose from clinical stage I to stage III. The polypeptides of the mol wt 55 and $31 \mathrm{kD}$ were exclusively bound by IgM and the proteins $66,58,39$, and $36 \mathrm{kD}$ exclusively by IgG. Based on the number of proteins visualized by single sera, IgM was the predominant isotype in stages I and II peaking in stage II, whereas in stage III IgG predominated. Considering the number of proteins recognized and the corresponding antibody isotype, a serologic differentiation between the three stages of the disease is feasible: within stage I and within stage III patients with different clinical signs had distinct antibody patterns. No clearcut pattern could be discriminated in stage II for patients with different settings. Immunoblotting yields a possible distinction between active infection and serological scar by the detection of specific antibody patterns. (Pediatr Res 26:377-382, 1989)
\end{abstract}

\section{Abbreviations}

ACA, acrodermatitis chronica atrophicans

ECM, erythema chronicum migrans

IFA, immunofluorescence assay

NC, nitrocellulose

TBS, Tris-buffered saline

Lyme disease is a tickborne disorder caused by the spirochete Borrelia burgdorferi (1). It may involve various organ systems. Based on the chronologic relationship to the tick bite the disease can be subdivided into three stages.

Stage I. Characteristically, the disease begins 4 to $20 \mathrm{~d}$ after a tick bite with a local inflammatory reaction called ECM: around the bite wound a red spot develops (macule or papule) which will be surrounded by a gradually enlarging annular lesion. As general symptoms headaches and/or arthralgias may occur.

Stage II. Weeks to months later, some patients present signs

Received February 20, 1989; accepted May 15, 1989.

Correspondence and reprints D. Nadal, Children's University Hospital, Steinwiesstrasse 75, CH-8032 Zurich, Switzerland.

Supported by the Federal Office of Public Health (Switzerland). of dissemination with cardiac disease, migratory musculoskeletal pain, or neurologic involvement, i.e. meningitis, seventh nerve palsy, or polyradiculitis.

Stage III. Weeks to years later, a few patients may develop arthritis, which untreated may become chronic with pannus formation and even with destructive erosion of cartilage and bone. Untreated neurologic syndromes may also become chronic or intermittently recurring. For unknown reasons every sign or finding can occur in isolation (2). Similarly, ACA, a dermatologic condition with erythema, shift of pigmentation, and frail skin, is a sign of the third stage of the illness. These lesions are mostly localized on the extensor surface of one extremity of adults after the third decade (3), but we observed them also in children (4).

First and second stage manifestations may resolve spontaneously. Because of the potential progression to chronic disturbances, however, antibiotic treatment is recommended in all stages, in children preferably with penicillin, in adults also with tetracyclines (2). Recently, successful treatment of late Lyme disease with cephalosporins has also been reported (5).

A history of tick bite and/or previous or actual ECM strongly suggests the diagnosis of Lyme disease. It should immediately be confirmed by determination of antibodies against $B$. burgdorferi (6-9). In atypical patients serology is essential, with the reservation that a positive titer to $B$. burgdorferi may represent a "serologic scar" due to a previous infection without actual interest.

The purpose of the present study was 1 ) to analyze the antibody response to $B$. burgdorferi antigens in children with different manifestations of Lyme disease by means of the immunoblot technique, 2) to investigate possible correlations of the antibody patterns to the stage of the disease, and 3) to evaluate the potential of immunoblotting to distinguish between active infection and serological scar.

\section{MATERIALS AND METHODS}

Patients. All patients treated at the University Children's Hospital of Zurich because of Lyme disease during the period from June 1985 to December 1987 were included in the study. The clinical data were gathered by chart review. Sera collected before treatment were stored at $-70^{\circ} \mathrm{C}$.

Materials. All chemicals as well as the instruments for electrophoresis and immunoblotting were purchased from LKB (Dübendorf, Switzerland) with the following exceptions: 4-chloro-1naphthol from Merck (Zurich, Switzerland), antisera for immunofluorescence assay from Behring (Marburg, FRG) and for immunoblotting from Dakopatts (IG-Instruments, Zurich, Switzerland), mol wt markers and NC paper from BioRad (Glatt- 
brugg, Switzerland), and human IgG from Schweizerisches Serum \& Impfinstitut (Bern, Switzerland).

Antigen preparation. B. burgdorferi B31 (ATCC 35210) was used for all antigen preparations. The spirochete was cultured in Barbour, Stonner, Kelly medium I (10) for $4-6$ d at $37^{\circ} \mathrm{C}$ until a final density of at least 20 organisms per 400 -fold magnification field was reached. Cells were harvested by centrifugation at $10000 \times g$ for $30 \mathrm{~min}$ at $4^{\circ} \mathrm{C}$.

$I F A$. Global Ig-IFA was performed by standard methods, as previously described (7). In brief, the harvested $B$. burgdorferi cells were three times resuspended in PBS and centrifuged at $10000 \times g$ for $30 \mathrm{~min}$ at $4^{\circ} \mathrm{C}$. The pellet was resuspended in PBS to a final concentration of 15-20 cells per 400-fold magnification field. Ten $\mu \mathrm{L}$ of the suspension were pipetted onto each of 10 circles of a slide, air dried, and frozen at $-75^{\circ} \mathrm{C}$. Fixation with acetone was done before use. Twenty-five $\mu \mathrm{L}$ of the patient's serum dilutions (2-fold steps beginning with 1:32) in PBS were incubated at $37^{\circ} \mathrm{C}$ for $30 \mathrm{~min}$. After washing three times with PBS and air drying, the slides were stained with a 1:60 dilution of fluorescein-isothiocyanate-labeled goat antihuman $\gamma$-globulin fraction, incubated for $30 \mathrm{~min}$, washed twice in PBS, and finally rinsed with deionized water. Titers $\geq 1: 64$ were regarded as significantly elevated (compared with 100 sera collected from healthy blood donors).

Electrophoresis. SDS-PAGE was performed in a modified version of the method described by Laemmli (11). Pelleted spirochetes were resuspended three times in cold PBS with $5 \mathrm{mM}$ $\mathrm{MgCl}_{2}$ and centrifuged for $30 \mathrm{~min}$ at $4^{\circ} \mathrm{C}$. The washed cells were resuspended in deionized water to reach a protein concentration of $0.5 \mathrm{~g} / \mathrm{L}$, measured according to the method of Lowry et al. (12). Electrophoresis of the spirochetal protein $(0.5 \mu \mathrm{g} / \mathrm{mm}$ gel $)$ was done on a $10 \%$ acrylamide gel $(18 \mathrm{~cm}$ plate, $1.5 \mathrm{~mm}$ gel thickness; 30:0.8 acrylamide:bisacrylamide) with 2-mercaptoethanol as reducing agent in the sample buffer. Two gels were run simultaneously in one chamber at a current of $60 \mathrm{~mA}$ at $12^{\circ} \mathrm{C}$ for approximately $5 \mathrm{~h}$ until a marker dye had traversed $10 \mathrm{~cm}$ of gel.

Separated polypeptides on the gels were stained with Coomassie Brilliant Blue R-250 or transferred to NC paper in a modified version of the method of Towbin et al. (13) using a Multiphor Novablot electrophoresis transfer unit (LKB). The transfer time was $1 \mathrm{~h}$ at a current of $150 \mathrm{~mA}$. To assess the efficiency of transfer, one longitudinal strip was cut from the NC sheet and stained with amido black and compared to immunoblots. Prestained molecular weight markers were phosphorylase b (79 400), BSA (66 200), ovalbumin (42 622), carbonic anhydrase (31 000), soybean trypsin inhibitor (21 500), and lysozyme (14 400).

Immunoblotting and detection of antigens. The NC paper containing transferred polypeptides was soaked for $1 \mathrm{~h}$ at room temperature in $2 \%$ BSA in TBS to saturate nonspecific proteinbinding sites. The NC sheets were dried between filter paper and stored at $4^{\circ} \mathrm{C}$. The NC was cut into 4-mm wide strips representing individual lanes from the gel. The strips were incubated individually with patient sera diluted 1:100 in TBS-0.05-Tween 20 overnight at room temperature on a rocking table. After washing the strips three times with TBS-0.05-Tween 20 , they were incubated for $1 \mathrm{~h}$ at room temperature with a 1:200 dilution of horscradish peroxidase-conjugated goat antibody to human $\gamma$ chain. After three more washings the $\mathrm{NC}$ were stained with 4chloro-1-naphthol for $20 \mathrm{~min}$. Finally, the staining was stopped by washing the strips once with TBS and twice with deionized water. Control samples included serum from five normal individuals and from two patients with syphilis, and in addition the conjugate alone.

To identify spirochetal proteins, the mAb H5332 which reacts with the outer membrane protein subunit of $B$. burgdorferi $\mathrm{B} 31$ (31 000) (14) and $\mathrm{H} 9724$ which binds to B. burgdorferi flagellin (4l 000) (15) were used (both kindly provided by A. G. Barbour, San Antonio, TX).
Rheumatoid factor. To avoid false-positive results in IgM detection, potentially present rheumatoid factor was removed by adsorption with latex particles coated with human IgG.

\section{RESULTS}

During the period from July 1985 to December 1987, 21 patients aged 4-15 y were treated for Lyme disease at the University Children's Hospital, Zurich. Diagnosis was based on history and clinical and serologic findings (Table 1). Three stages of the disease were distinguished. None of the patients in the stages II and III remembered previous ECM and no patient in stage III had presented symptoms compatible with stage II.

Immunoblotting. Antibodies to B. burgdorferi antigens could in each case be identified as binding to individual polypeptides (Tables 2 and 3). Ig bound to as many as 17 distinct proteins with mol wt of $41,83,62,47 / 48,60 / 61,29,55,66,39,22,17$ / $18,58,42,31,75,36$, and $23 \mathrm{kD}$ (listed in order of frequency). Two of these polypeptides were bound exclusively by IgM ( 55 and $31 \mathrm{kD})$ and four others exclusively by $\operatorname{IgG}(66,58,39$, and $36 \mathrm{kD}$ ) (Figs. 1 and 2).

Sera of the four patients with stage I (patients 1-4) contained Ig binding to three to 10 polypeptides. All sera had IgM reacting with two to seven polypeptides and IgG reacting with one to six. The $41-\mathrm{kD}$ protein was bound by $\operatorname{IgG}$ from all sera and by IgM from all but one. Both patients with ECM had in common the binding of $\operatorname{IgM}$ to the $31-\mathrm{kD}$ polypeptide and of $\mathrm{IgG}$ to the 29 $\mathrm{kD}$ protein, a pattern not found in the two children suffering from headaches.

The sera of the nine patients assigned to stage II (patients 513) reacted with four to 10 proteins, IgM with four to seven, and IgG to as many as six. Compared with stage I, six additional proteins were visualized. Furthermore, in stage II, IgM bound to more proteins per serum than in stage I (mean 5.7 bands versus 4.3), whereas the number of bands per serum visualized by IgG did not differ (mean 2.9 versus 3 ). A constant finding in all sera was the binding of the $83-\mathrm{kD}$ protein by $\mathrm{IgM}$ and/or $\mathrm{IgG}$ and in all sera but one the reaction with the $41-\mathrm{kD}$ polypeptide. The patient with polyneuropathy was the only one with no antibodies against the $41-\mathrm{kD}$ protein and both patients with paresthesia were the only ones with IgM but no IgG reacting with this protein. Moreover, these latter two patients and the one with meningitis were unique with IgM binding to both proteins 60 / 61 and $47 / 48 \mathrm{kD}$.

Ig in the sera of the eight patients classified to stage III (patients 14-21) were found to react with eight to 13 polypeptides, IgM with as many as five, and IgG with six to 12 . No additional polypeptides beside those also seen in stages I and II were visualized. Binding of IgM was detectable in all sera except in one from a patient with arthritis, but it involved a smaller number of proteins than in stage II (mean 2.5 bands per serum with reacting IgM versus 5.7). IgG, however, reacted with substantially more proteins than in stage II (mean 10 yersus 2.9). In stage III every serum bound IgG to the four proteins $83,60 / 61$, 41 , and $29 \mathrm{kD}$, a feature not found in stages I and II. Moreover, in stage III all sera but one contained IgG binding to the $58-\mathrm{kD}$ polypeptide which was not visualized by stage II sera. Furthermore, antibodies binding to the $60 / 61-\mathrm{kD}$ protein were exclusively IgG. Anti-55-kD protein antibodies, commonly found in stages I and II, were exceptional. All patients with arthritis except one differed from those with ACA by the absence of antibodies binding to the 75-kD polypeptide and all except two by the lack of $\mathrm{Ig}$ reacting with the $17 / 18-\mathrm{kD}$ protein. Among the patients with arthritis one (patient 16) differed markedly from the others by absent antibodies reacting with the 58-, 47/48-, 41-, and 22$\mathrm{kD}$ polypeptides.

No reactions were seen with the sera from the five normal individuals and with the conjugate alone. The two syphilis sera showed weak reactions: one with $\mathrm{IgG}$ against the proteins 41 and $29 \mathrm{kD}$, and $\mathrm{IgM}$ versus $60 / 61 \mathrm{kD}$, the other $\mathrm{IgG}$ versus $83 \mathrm{kD}$. 
IFA titers. The titers of anti-B.burgdorferi-Ig ranged from 1:128 to 1:4096 (Table 1). Patients with Lyme disease in the second or third stage tended to have higher titers than patients in the initial stage, but there was no strict correlation between elevation of the titer and the stage of the disease.

\section{DISCUSSION}

To our knowledge, our study is the first focusing on patterns of antibodies reacting with polypeptides of $B$. burgdorfer $i \mathrm{~B} 31$ in children with different stages of Lyme disease. Between the three

Table 1. Characteristics of 21 patients with different manifestations of Lyme disease

\begin{tabular}{|c|c|c|c|c|c|c|}
\hline Stage & $\begin{array}{l}\text { Patient } \\
\text { No. }\end{array}$ & Sex & $\begin{array}{c}\text { Age } \\
\text { (y) }\end{array}$ & Symptoms* & $\begin{array}{c}\text { Tick bite } \\
\text { (wk before) }\end{array}$ & $\frac{\text { Borrelia burgdorferi }}{\text { IFA titer } \dagger}$ \\
\hline \multirow[t]{4}{*}{ Stage I } & 1 & $\mathrm{~F}$ & 8 & Headache & None & 256 \\
\hline & 2 & $\mathrm{~F}$ & 9 & Headache & None & 256 \\
\hline & 3 & $\mathrm{M}$ & 10 & $\mathrm{ECM}$ & -3 & 128 \\
\hline & 4 & $\mathrm{~F}$ & 4 & $\mathrm{ECM}$ & -18 & 128 \\
\hline \multirow[t]{9}{*}{ Stage II } & 5 & M & 6 & $\mathrm{PN}$ & None & 128 \\
\hline & 6 & $\mathrm{~F}$ & 10 & Paresthesia & $-?$ & 512 \\
\hline & 7 & $\mathrm{~F}$ & 13 & Paresthesia & None & 128 \\
\hline & 8 & $\mathrm{~F}$ & 14 & SNP & None & 256 \\
\hline & 9 & $\mathrm{M}$ & 6 & SNP & -4 & 2048 \\
\hline & 10 & $\mathbf{M}$ & 5 & SNP & None & 256 \\
\hline & 11 & $\mathrm{~F}$ & 15 & SNP & -5 & 128 \\
\hline & 12 & $\mathrm{M}$ & 9 & SNP & -12 & 1024 \\
\hline & 13 & M & 12 & Meningitis & -5 & 512 \\
\hline \multirow[t]{8}{*}{ Stage III } & 14 & M & 8 & Gonarthritis & None & 1024 \\
\hline & 15 & M & 6 & Gonarthritis & None & 128 \\
\hline & 16 & $\mathrm{~F}$ & 7 & Gonarthritis & $-?$ & 256 \\
\hline & 17 & $\mathrm{M}$ & 15 & Gonarthritis & None & 4096 \\
\hline & 18 & $\mathrm{~F}$ & 7 & Gonarthritis & None & 1024 \\
\hline & 19 & $\mathrm{~F}$ & 11 & Gonarthritis & None & 1024 \\
\hline & 20 & $\mathrm{M}$ & 10 & $\mathrm{ACA}$ & -52 & 4096 \\
\hline & 21 & $\mathrm{M}$ & 12 & $\mathrm{ACA}$ & None & 4096 \\
\hline
\end{tabular}

* PN, polyneuropathy; SNP, seventh nerve palsy.

$\uparrow$ Indirect immunofluorescence assay: global titer of specific immunoglobulins.

Table 2. Patterns of IgM antibody binding to polypeptides of B. burgdorferi in 21 children with different stages of Lyme disease as determined by immunoblotting

\begin{tabular}{|c|c|c|c|c|c|c|c|c|c|c|c|c|c|c|c|c|c|c|}
\hline \multirow[b]{2}{*}{ Stage } & \multirow[b]{2}{*}{ Patient } & \multicolumn{17}{|c|}{ Protein mol wt (kD) } \\
\hline & & 83 & 75 & 66 & 62 & $60 / 61$ & 58 & 55 & $47 / 48$ & 42 & 41 & 39 & 36 & 31 & 29 & 23 & 22 & $17 / 18$ \\
\hline \multirow[t]{4}{*}{ Stage I } & 1 & & & & 1 & & & I & I & & & & & & & & & I \\
\hline & 2 & 1 & & & & & & & & & 1 & & & & & & & \\
\hline & 3 & 1 & & & 1 & & & 1 & & & 1 & & & 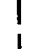 & & & 1 & 1 \\
\hline & & & & & & & & & & & & & & & & & & \\
\hline \multirow{9}{*}{ Stage II } & 5 & 1 & & & 1 & & & 1 & I & & & & & & & & & \\
\hline & 6 & & & & & 1 & & 1 & 1 & & 1 & & & & & & & \\
\hline & 7 & 1 & & & 1 & 1 & & 1 & 1 & & 1 & & & & & & & \\
\hline & 8 & I & & & & 1 & & 1 & & & 1 & & & 1 & & & & 1 \\
\hline & 9 & I & & & 1 & & & 1 & 1 & & 1 & & & & & & & \\
\hline & 10 & & & & I & & & 1 & & & I & & & 1 & & & 1 & 1 \\
\hline & 11 & I & & & 1 & 1 & & 1 & & & 1 & & & 1 & & & & 1 \\
\hline & 12 & 1 & I & & 1 & & & & 1 & & I & & & & & 1 & & 1 \\
\hline & 13 & 1 & & & 1 & 1 & & & 1 & & 1 & & & & & 1 & & 1 \\
\hline \multirow[t]{6}{*}{ Stage III } & 14 & & & & & & & & & & & & & & & & & \\
\hline & 15 & & & & 1 & & & 1 & I & & I & & & I & & & & 1 \\
\hline & $\begin{array}{l}16 \\
17\end{array}$ & & & & 1 & & & 1 & & 1 & 1 & & & 1 & & & & \\
\hline & 18 & 1 & & & 1 & & & & & & & & & & & & & \\
\hline & 19 & i & & & 1 & & & & & & & & & & & & & \\
\hline & $\begin{array}{l}20 \\
21\end{array}$ & i & & & 1 & & & & I & & 1 & & & 1 & 1 & & & \\
\hline
\end{tabular}


Table 3. Patterns of IgG antibody binding to polypeptides of B. burgdorferi in 21 children with different stages of Lyme disease as determined by immunoblotting

\begin{tabular}{|c|c|c|c|c|c|c|c|c|c|c|c|c|c|c|c|c|c|c|}
\hline \multirow[b]{2}{*}{ Stage } & \multirow[b]{2}{*}{ Patient } & \multicolumn{17}{|c|}{ Protein mol wt (kD) } \\
\hline & & 83 & 75 & 66 & 62 & $60 / 61$ & 58 & 55 & $47 / 48$ & 42 & 41 & 39 & 36 & 31 & 29 & 23 & 22 & $17 / 18$ \\
\hline \multirow[t]{4}{*}{ Stage I } & 1 & & & & & & & & & & 1 & & & & & & & \\
\hline & 2 & & & & & & & & & & 1 & & & & & & & 1 \\
\hline & 3 & 1 & & & & & 1 & & & & 1 & & 1 & & 1 & & & 1 \\
\hline & 4 & & & & & & & & & & 1 & & & & 1 & & & \\
\hline \multirow[t]{8}{*}{ Stage II } & 5 & & & & & & & & & & & & & & & & & \\
\hline & 6 & 1 & & & & & & & & & & & & & & & & \\
\hline & 7 & I & & & & & & & & & & & & & 1 & & & 1 \\
\hline & 8 & & & & & & & & & & 1 & & & & & & & \\
\hline & 9 & & & & & & & & & & 1 & 1 & & & & & & 1 \\
\hline & 10 & 1 & & & & & & & & 1 & I & 1 & & & & & & \\
\hline & 11 & & & I & & & & & & & 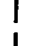 & 1 & & & & & & \\
\hline & $\begin{array}{l}12 \\
13\end{array}$ & 1 & & 1 & & 1 & & & & 1 & 1 & 1 & & & & & 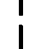 & 1 \\
\hline \multirow{8}{*}{ Stage III } & 14 & I & & & & 1 & 1 & & 1 & 1 & I & 1 & & & 1 & & & \\
\hline & 15 & 1 & & 1 & & I & i & & i & & i & i & & & 1 & & 1 & 1 \\
\hline & 16 & I & & 1 & & I & & & & & 1 & i & & & i & & & \\
\hline & 17 & 1 & & 1 & & I & 1 & & I & & 1 & ! & 1 & & 1 & & 1 & \\
\hline & 18 & 1 & & 1 & & I & 1 & & I & 1 & I & 1 & & & I & & i & \\
\hline & 19 & 1 & I & 1 & 1 & I & 1 & & I & & 1 & 1 & & & 1 & & 1 & 1 \\
\hline & 20 & 1 & I & 1 & & I & 1 & & I & 1 & 1 & & & & 1 & I & 1 & 1 \\
\hline & 21 & 1 & 1 & 1 & & 1 & I & & 1 & 1 & 1 & 1 & & & 1 & & I & 1 \\
\hline
\end{tabular}

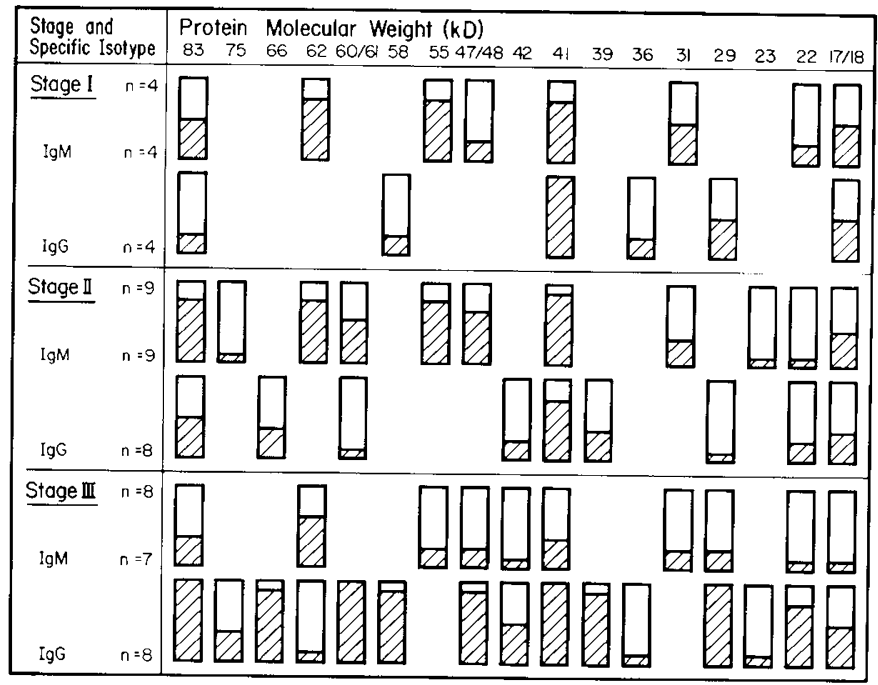

Fig. 1. Frequency of $\operatorname{IgM}$ and $\operatorname{IgG}$ binding to Borrelia burgdorferi B31 proteins in relation to stage of Lyme disease. Hatched areas of bars represent the percent of subjects positive for anti-protein antibody, while hatched plus open bars represent total number tested.

stages of the disease and in part also between clinical settings within the same stage we find considerable variations in number and nature of polypeptides bound and of binding isotypes.

The number of polypeptides detected in this study is similar $(16,17)$ or higher than in other reports $(18-20)$. This might be due to several causes.

1) Technical differences-we did not add protease inhibitors during polypeptide separation by SDS-PAGE. Thus, insufficient breakdown of polypeptide dimers of $B$. burgdorferi might have resulted in supplementary or distinct bands (16). In addition, we transferred the polypeptides from SDS to NC by a semidry horizontal electrophoretic method which was not applied in other similar studies and which might also influence the results.

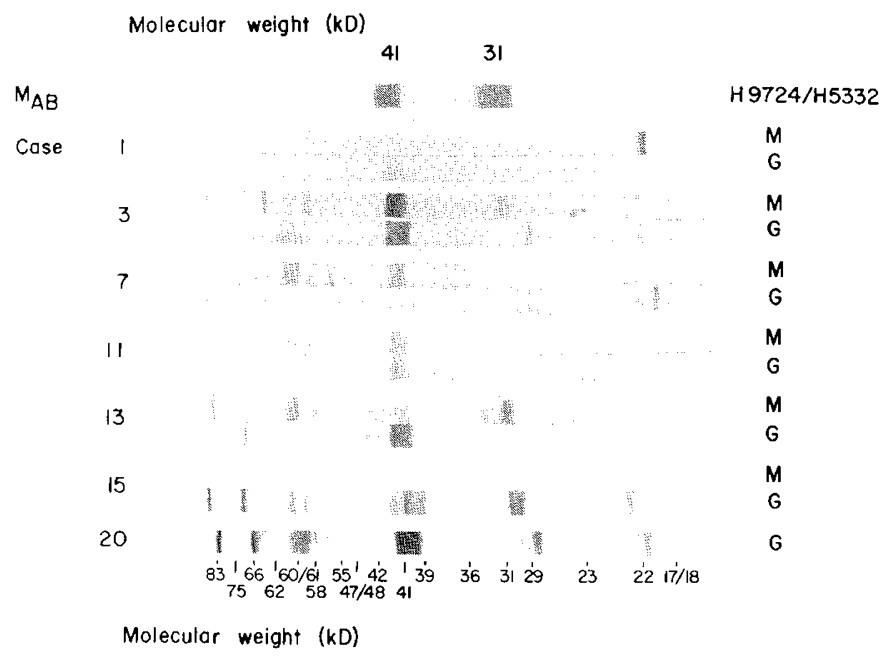

Fig. 2. Examples of immunoblot findings in respect to $\mathrm{IgM}$ and $\mathrm{IgG}$ to $B$. burgdorferi B31 in patients with different stages of Lyme disease. $\mathrm{M}_{\mathrm{AB}}$ denotes MAb (H9724 binds to $41-\mathrm{kD}$ and $\mathrm{H} 5332$ to $31-\mathrm{kD}$ protein).

2) The strains of $B$. burgdorferi used as antigen might influence the detection of polypeptides of different molecular weight.

3) The geographical areas might be populated by antigenically different $B$. burgdorferi strains, which would elicit divergent host responses.

4) Stages of Lyme disease in our patients are different, and we compare them. Previous authors included patients with the same clinical setting or patients progressing through different stages. All the polypeptides visualized in our analysis, however, correspond to proteins previously observed in electrophoreses of the $B$. burgdorferi strain B31 (21).

In our study, $\operatorname{IgM}$ is the predominant isotype in stage I and even more pronounced in stage II, whereas in stage III the major isotype is IgG. False-positive results of IgM detection due to rheumatoid factor were ruled out. These findings are in agree- 
ment with previous results in adults with early Lyme disease (16, 19). Inasmuch as we did not separate the isotypes before incubation of the sera, a competitive advantage of $\operatorname{IgG}$ over $\operatorname{IgM}$ in their binding to the polypeptide antigens cannot be excluded.

In our study with cross-sectional character, the scope of proteins bound by antibodies enlarged remarkably from stage I to stage III. A similar finding was reported from a longitudinal analysis in adults progressing through the different stages of Lyme disease (18). This appearance of new protein bands during the course of the illness suggests the persistence of $B$. burgdorferi within the host: the longer the bacterium is not eliminated, the more additional antigens, corresponding to protein bands, will be recognized by the host's immune system. Indeed, viable $B$. burgdorferi has been isolated from individuals with different clinical stages and settings of Lyme disease (2).

We and others (16) have demonstrated that the binding of antibodies in stage I is not restricted to the $41-\mathrm{kD}$ protein, which is associated to the borrelial flagellum (22). This contrasts with findings in previous studies pointing out the ability of the $41-\mathrm{kD}$ protein to suppress the immune response in early Lyme disease $(18,19)$. Furthermore, we have shown that patients with stage I may exhibit distinct antibody patterns, depending on their clinical setting: sera of patients with ECM recognize the proteins 31 and $29 \mathrm{kD}$, but patients with headaches do not. The antibody pattern of the only child with meningitis is similar to that of reported patients $(17,20)$. Despite divergences between the patients with different manifestations, we cannot discriminate a clear-cut antibody pattern for each setting in stage II. In stage III, however, we find serologic patterns in children with arthritis which differ from those in patients with ACA. The antibody panels in children with arthritis are analogous to those of the few reported patients with the same setting (18). In contrast to a previous study (22), our patients with ACA recognized more polypeptides than patients with arthritis.

In our study, none of the children with stage III had previous ECM or neurologic involvement and none with stage II had a history of ECM, and this is consistent with recent reports in the literature. Thus, the question arises, whether the classification of Lyme disease into three stages is justified. Applying this classification, we and others (18) find, as already mentioned, an increase in the number of proteins recognized from stage I to III. This has been explained by the different duration of persistence of $B$. burgdorferi within the host. Therefore, classification into three stages seems appropriate. But taking into account the patients with an atypical history, another question arises, i.e. whether the clinical expression of Lyme disease is determined by properties of the infecting $B$. burgdorferi strain with particular antigenic components, or rather by the individual immune response of the host.

The clinical presentation of $B$. burgdorferi infection varies geographically. In northern Europe neurologic disorders and ACA predominate, whereas in the United States joint involvement seems to be more frequent. These observations could be explained by a hypothesis of different strains causing different diseases. In fact, the polypeptides of Scandinavian and North American B. burgdorferi isolates are not identical (23), and strains from central Europe have recently been described in correlation with diverse clinical manifestations (24).

However, it is still obscure why some individuals overcome infection with $B$. burgdorferi without symptoms, and why in some patients Lyme disease is restricted, e.g. to ECM, and why in others, with or without a typical history, it develops into a chronic disorder. Individual proneness of the host to such different evolution, analogous to HLA-B27-associated arthritis, could provide an explanation. In fact, the HLA-phenotype DR2 has been reported with significant preponderance in patients with chronic Lyme disease $(25,26)$.

In patients lacking the typical history of tick bite and/or of ECM, the diagnosis of Lyme disease has to rely on serologic findings. Antibodies against $B$. burgdorferi, however, may also be detected in asymptomatic individuals. In endemic areas up to $9 \%$ of the population were found to be seropositive (27). So far, no definite laboratory test differentiates between specific IgG in active disease from the asymptomatic antibody response. Such a distinction would be of therapeutic relevance to avoid unnecessary antibiotic treatment.

Indirect indicators for recent or actual infection are seroconversion or presence of specific IgM. But early seroconversion in Lyme disease is rarely detected because first symptoms may considerably lag behind the infection. Moreover, detection of IgM by IFA or ELISA test is enigmatic (6). Immunoblotting could facilitate the distinction between active infection and serological scar: first by detection of specific IgM and second by visualization of the complex pattern of antibodies binding to many polypeptides. Several investigators $(16,18)$ have stressed the superiority over other serologic methods of immunoblotting in detection of IgM. All these data are quite suggestive for the value of antigen-antibody patterns in close correlation with the clinical evolution.

\section{REFERENCES}

1. Steere AC, Grodzicki RL, Kornblatt AN, Craft JE, Barbour AG, Burgdorfer W, Schmid GP, Johnson E, Malawista SE 1983 The spirochetal etiology of Lyme disease. N Engl J Med 308:733-740

2. Stechenberg BW 1988 Lyme disease: the latest great imitator. Pediatr Infect Dis J 7:402-409

3. Åsbrink E, Hovmark A, Hederstedt B 1984 The spirochetal etiology of acrodermatitis chronica atrophicans Herxheimer. Acta Dermatol Venereol 64:506-512

4. Nadal D, Gundelfinger R, Flueler U, Boltshauser E 1988 Acrodermatitis chronica atrophicans. Arch Dis Child 63:72-74

5. Dattwyler RJ, Halperin JJ, Volkman DJ, Luft BJ 1988 Treatment of late Lyme borreliosis-randomised comparison of ceftriaxone and penicillin. Lancet 1:1191-1194

6. Craft JE, Grodzicki RL, Steere AC 1984 Antibody response in Lyme disease: Evaluation of diagnostic tests. J Infect Dis 149:789-795

7. Magnarelli LA, Meegan JM, Anderson JF, Chappell WA 1984 Comparison of an indirect fluorescent-antibody test with an enzyme-linked immunosorbent assay for serological studies of Lyme disease. J Clin Microbiol 20:181-4

8. Russell H, Sampson JS, Schmid GP, Wilkinson HW, Plikaytis B 1984 Enzymelinked immunosorbent assay and indirect immunofluorescence assay for Lyme disease. J Infect Dis 149:465-470

9. Stiernstedt G, Eriksson G, Enfors W, Jörbeck H, Svenungsson B, Sköldenberg B Granström M 1986 Erythema chronicum migrans in Sweden: clinical manifestations and antibodies to Ixodes ricinus spirochete measured by indirect immunofluorescence and enzyme-linked immunosorbent assay. Scand J Infect Dis 18:217-224

10. Barbour AG 1984 Isolation and cultivation of Lyme disease spirochetes. Yale $\mathrm{J}$ Biol Med 57:521-525

11. Laemmli UK 1970 Cleavage of structural proteins during the assembly of the head of bacteriophage T4. Nature 227:680-685

12. Lowry OH, Rosebrough NJ, Farr AL, Randall RJ 1951 Protein measurement with Foli phenol reagent. J Biol Chem 193:265-275

13. Towbin $H$, Staehelin T, Gordon J 1979 Electrophoretic transfer of proteins from polyacrylamide gels to nitrocellulose sheets: procedure and some applications. Proc Natl Acad Sci USA 76:4350-4354

14. Barbour AG, Tessier S, Todd WJ 1983 Lyme disease spirochetes and ixodic tick spirochetes share a common surface antigenic determinant defined by a monoclonal antibody. Infect Immun 45:94-100

15. Barbour AG, Hayes SF, Heiland RA, Schrumpf ME, Tessier S 1986 A Borreliaspecific monoclonal antibody binds to a flagellar epitope. Infect Immun 52:549-554

16. Grodzicki RL, Steere AC 1988 Comparison of immunoblotting and indirect enzyme-linked immunosorbent assay using different antigen preparations for diagnosing early Lyme disease. J Infect Dis 157:790-797

17. Karlsson M, Möllegard I, Stiernstedt G, Henriksson AM, Wretlind B 1988 Characterization of antibody response in patients with Borrelia meningitis. Serodiag Immunother Inf 2:375-386

18. Craft JE, Fischer DK, Shimamoto GT, Steere AC 1986 Antigens of Borrelia burgdorferi recognized during Lyme disease. J Clin Invest 78:934-939

19. Coleman JL, Benach JL 1987 Isolation of antigenic components from the Lyme disease spirochete: their role in early diagnosis. J Infect Dis 155:756765

20. Wilske B, Schierz G, Preac-Mursic V, von Busch K, Kühbeck R, Pfister HW, Einhäupl K 1986 Intrathecal production of specific antibodies against Borrelia burgdorferi in patients with lymphocytic meningoradiculitis (Bannwarth's syndrome). J Infect Dis 153:304-314

21. Green RT, Walker RL, Burgess EC, Levine JF 1988 Heterogeneity in immu- 
noblot patterns obtained by using four strains of Borrelia burgdorferi and sera from naturally exposed dogs. J Clin Microbiol 26:2287-2291

22. Wilske B, Preac-Mursic V, Schierz G, Gueye W, Herzer P, Weber K 1988 Immunochemische Analyse der Immunantwort bei Spätmanifestationen der Lyme Borreliose. Zbl Bakt Hyg A 267:549-558

23. Barbour AG, Heiland RA, Howe TR 1985 Heterogeneity of major proteins in Lyme disease Borreliae: a molecular analysis of North American and European isolates. J Infect Dis 152:478-484

24. Wilske B, Preac-Mursic V, Schierz G, Busch KV 1986 Immunochemical and immunological analysis of European Borrelia burgdorferi strains. Zbl Bakt Hyg A 263:92-102

25. Kristoferitsch W, Mayr WR, Partsch H, Neumann R, Stanek G 1986 HLA-Dr in Lyme borreliosis. Lancet 2:278

26. Steere AC, Duray PH, Butcher EC 1988 Spirochetal antigens and lymphoid cell surface markers in Lyme synovitis. Arthritis Rheum 31:487-495

27. Satz N, Ackermann R, Gern L, Aeschlimann A, Ott A, Knoblauch M 1988 Zur Epidemiologie der Infektion mit Borrelia burgdorferi. Schweiz Med Wochenschr 118:422-426

\section{Announcements}

\section{Abstract Deadline}

The American Pediatric Society and The Society for Pediatric Research announce the abstract deadline for the 1990 Annual Meeting (May 7-11, 1990, Anaheim Hilton \& Convention Center, Anaheim, CA) has been set as January 4, 1990.

For further information contact: 2650 Yale Blvd., S.E., Suite 104, Albuquerque, NM 87106 (505)764-9099.

Society for Behavioral Pediatrics 7th Annual Meeting

The Society for Behavioral Pediatrics will conduct its 7th Annual Meeting on November 9-10, 1989 at the Royal Sonesta Hotel in Cambridge, Massachusetts. A special session honoring Dr. T. Berry Brazelton will be held November 11. For further information and registration forms, contact Ms. Noreen Spota at (215) 248-9168. 